\title{
(6) OPEN ACCESS \\ Parallel contagion phenomenon of concordant mental disorders among married couples: a nationwide cohort study
}

\author{
Jong-Yi Wang, ${ }^{1}$ Ming-Hong Hsieh, ${ }^{2,3}$ Pei-Ching Lin, ${ }^{4}$ Chiu-Shong Liu, ${ }^{5,6}$ \\ Jen-De Chen ${ }^{7}$
}

'Department of Health Services Administration, China Medical University, Taichung, Taiwan ${ }^{2}$ Department of Psychiatry, Chung Shan Medical University Hospital, Taichung, Taiwan ${ }^{3}$ School of Medicine, Chung Shan Medical University, Taichung, Taiwan

${ }^{4}$ Tele-Healthcare Center Kaohsiung Medical University Chung-Ho Memorial Hospital, Kaohsiung, Taiwan

${ }^{5}$ Department of Family Medicine, China Medical University Hospital, Taichung, Taiwan ${ }^{6}$ Department of Medicine, China Medical University, Taichung

Taiwan

${ }^{7}$ Department of Sports, National Changhua University of Education, Changhua, Taiwan

\section{Correspondence to}

Dr Jong-Yi Wang, Department of Health Services Administration, China Medical University, No.91, Hsueh-Shih Road, Taichung 40402, Taiwan; ericwang@mail.cmu.edu.tw

Received 25 August 2016 Revised 12 December 2016 Accepted 5 February 2017 Published Online First 20 February 2017



To cite: Wang J-Y, Hsieh M-H, Lin P-C, et al. J Epidemiol Community Health 2017:71:640-647.

\section{ABSTRACT}

Background The aggregation of mental disorders in couples, as reported by prior research, indicates the effect of familial environments and warrants attention. However, the concordant categories of mental disorders in couples remain unclear. This study investigated spousal concordance for the category of mental disorders among couples throughout Taiwan by using factors associated with such disorders.

Methods 5643 couples in the 2002-2013 Taiwan National Health Insurance Research Database were analysed and compared with propensity-matched 5643 non-couples. Twelve independent variables, including spouse and shared characteristics, and the category of mental disorders were analysed, mainly by using multinomial logistic regression.

Results The determined prevalence rates for concordant categories of mental disorder were $0.19 \%$ for affective disorders, $6.96 \%$ for anxiety disorders, and $3.15 \%$ of other mental disorders. Multinomial logistic regression results revealed that two spouses were significantly more likely to be diagnosed with the same category of the aforementioned mental disorders (ORs $=2.914,1.776$ and 1.727, respectively). Other associated factors included gender, age, occupation, comorbidity and region. The odds of concordances were significantly higher in couples than in non-couples.

Conclusions A category of mental disorder in one spouse is a determinant of that in the other spouse. This study extended the emotional contagion theory to the phenomenon of parallel contagion to reflect the three concordances, suggesting a direction of family-based mental health intervention, particularly prevention for the same category of mental disorders in couples.

Policymakers should strengthen the coping strategies of the caring spouse and external support system to psychiatrically vulnerable families.

\section{INTRODUCTION}

Mental illness is a growing problem worldwide. ${ }^{1}$ Genetic relatedness has been reported to be a determinant of mental disorders among family members. $^{2} 3$ Nevertheless, recent studies have reported the aggregation of mental disorders in couples who did not share genetic factors. A study revealed that depression is likely $(\mathrm{OR}=2.08)$ to occur in both married partners if either of them experienced depression. ${ }^{4}$ A longitudinal study further indicated that somatic and psychiatric morbidity of one partner could affect the psychiatric condition of the other married partner. ${ }^{5}$ Based on the existing literature, concordance of specific mental disorders in couples includes depression, ${ }^{4-6}$ anxiety ${ }^{7}$ and substance abuse. ${ }^{8-10}$ However, inconclusive and incomplete findings still exist among related research. Furthermore, existing concordance studies either aimed at a certain disorder or examined a relatively small number of associated factors. Hence, determining concordance for the category of mental disorders among couples out of a complete spectrum of mental disorders by using comprehensive factors is highly demanding.

Previous studies have explained the phenomenon of spousal concordance of diseases by using 'assortative mating' and 'cohabitation effects'. ${ }^{11-13}$ Assortative mating refers to the tendency of mate selection depending on the similarity of individual characteristics, including values and personality traits. Cohabitation effects explicate the significance of common household environmental influences, including the sharing of numerous aspects of lifestyle, after marriage. In addition, because marital relationship is reciprocal and interdependent, concordance of mental disorders in couples can be further explained by 'emotional contagion'. ${ }^{14}$ Marriage is an imperative resource during stress. ${ }^{15}$ Accordingly, the emotional state of a spouse bidirectionally influences that of the partner. ${ }^{16}$ Mutual experience of stress can delineate the resembling depression symptomatology between both spouses. In particular, higher levels of depression in husbands could predict the subsequent exacerbation of depressive symptoms in wives. $^{17}$ Furthermore, emotional similarity induced by the sharing of stressors and emotional support could unravel the phenomenon of mental illness transmission from one spouse to other spouse. ${ }^{18}$ The theory of emotional contagion was primarily applied to depict the concordance of depression in couples. ${ }^{16} 19$ However, it is conceivable that the initial similarity between both spouses in individual characteristics from the time of mate selection can expand to subsequently gradual conformity in health behaviours. ${ }^{20-22}$ Affect and behaviour similarities could potentially lead to even an exposure to various types of disorders, other than depression, under the effects of durable cohabitation in the common ecological system, which involves family and work environment as the microsystem and mesosystem, respectively. ${ }^{23}$ Therefore, the current research extended the concordance of depression to a hypothetical concordance of other categories of mental disorders, including anxiety and others, on the basis of assortative mating, cohabitation effects and emotional contagion jointly. 
For examining the effect of one mentally ill spouse on the other spouse, previous studies have adopted gender and age as two major related factors. ${ }^{4} 51424$ A higher risk of mental disorders has been typically associated with women and old ages. ${ }^{4}$ Low household income has been closely tied to high psychiatric morbidity. ${ }^{25}$ In addition, research has indicated that the presence of physical diseases such as diabetes and cancer was associated with the risk of mental disorders. ${ }^{26} 27$ Therefore, comorbidity in each spouse was considered a factor associated with the occurrence of mental disorders. Moreover, a marked discrepancy in prevalence rates of mental disorders, including depression, anxiety and substance abuse, was present across various occupations. ${ }^{28-31}$ Environmental characteristics might be associated with the occurrence of mental diseases. ${ }^{8} 23$ However, the findings remained inconsistent. The association between the characteristics of geography where the family was located and the occurrence of mental disorders substantiates the need for investigation.

Scarce data have reported the concordant categories of mental disorders; therefore, this study investigated spousal concordance of the category of physician-diagnosed mental disorders by using all potential associated factors of mental disorders addressed in previous studies. Hence, the concordance of mental disorders in couples could be fully determined.

\section{METHODS}

\section{Hypothesis and research design}

This study hypothesised that, after controlling for the effects of related factors including individual and shared characteristics, the category of mental disorders diagnosed in one spouse is associated with that diagnosed in the other spouse. This hypothesis of categorical concordance was tested in a longitudinal population-based case-control design, analysing nationwide data of married couples in Taiwan. The study was approved by the institutional review board at China Medical University Hospital, Taiwan.

\section{Data source and study sample}

The National Health Insurance (NHI) programme, launched in 1995, provides comprehensive healthcare to more than $99.7 \%$ of the residents in Taiwan ( $\mathrm{N}=23.50$ million). This retrospective study employed the 2002-2013 National Health Insurance Research Database (NHIRD), which includes data for one million randomly sampled beneficiaries and thus entirely represents all enrolees in Taiwan. The NHIRD is maintained by Taiwan's National Health Research Institutes and records all original medical claims under the universal NHI programme.

The couple could be identified from the NHIRD only under the condition of one spouse enrolling being a health insurance insured with a certain occupation and the other spouse being a dependent of this insured spouse. In addition, to ascertain the initial diagnosis of mental disorders, patients diagnosed with mental disorders (International Classification of Diseases, Ninth Revision, Clinical Modification (ICD-9-CM): 290.x-319.x) in 2002 were excluded from the study. This study sought to retrieve all the identifiable couples. Accordingly, a total of 5643 married couples (5643 insured and dependent spouses) were identified for further analysis. To increase the strength of inference, the case group (couples) was matched by gender, age and comorbidity with the control group (non-couples) through 1:1 propensity score matching (PSM). This procedure was performed twice because there are two members in one couple (dual PSM). The results indicated that the couples and the noncouples were not significantly different in the three propensity score-matched variables (all $\mathrm{p}=1$ ), indicating that the two groups qualified for comparison. Consequently, 5643 couples and 5643 non-couples were eligible for subsequent analysis.

\section{Variables}

The category of mental disorders among dependent spouses served as the outcome variable that was categorically defined in this study. The category of mental disorders among insured and dependent spouses, with the former functioning as a major independent variable, both identically included affective disorders, anxiety disorders and other mental disorders, as addressed by previous studies. On the theoretical basis of emotional contagion and affect similarity, all affective disorders were applied, instead of merely depression. The categorisation of affective disorders involved any of the following ICD-9-CM codes: 296.0x, 296.2x, 296.3x, 296.4x, 296.5x, 296.6x, 296.7, 296.8x, 296.9x, 300.4, 301.13, 309.0, 309.1 and 311. The coding for anxiety disorders in this study included $300.0 \mathrm{x}$, $300.2 x, 300.3$, 308. $x$ and 309.81. The remaining 290.x-319.x diagnoses other than affective disorders and anxiety disorders were classified as other mental disorders. Mental disorders of low incidence, such as substance abuse, were merged into the category of 'other' to avoid unstable statistical estimations engendered by low frequency. Spouses were possibly not diagnosed with any mental disease throughout the observation period. Therefore, no mental disorders were added as one status category in the variables. Concordance in this study was defined as a clinical state in which insured and dependent spouses were diagnosed with any of the same category of mental disorders, including affective, anxiety and other mental disorders; otherwise, discordance or no concordance would be reported.

As the aforementioned studies indicated reciprocity of marital relationship in one common environment, the present research grouped the following independent variables that might be associated with the occurrence of mental disorder into three categories. (1) Insured spouse characteristics including category of mental disorders; (2) dependent spouse characteristics; (3) shared ecological characteristics. Age did not pass a normality test and thus was transformed into five ordinal levels according to the frequency distribution. Occupation, premium-based monthly salary, catastrophic illness and injury, and region were defined from the official classifications of the NHI programme. Since, Taiwan allows only opposite-sex marriage, only the gender of the dependent was adopted to eliminate predictable collinearity. Comorbidity was calculated using the Charlson Comorbidity Index (CCI), ${ }^{32}$ a frequently used measure in clinical research. After original scoring from 0 to 6 by weighting ICD-9-CM codes for each patient, this study classified comorbidity into 0 (without comorbidity) and 1 (with comorbidity) because of the low-frequency distribution in CCI scores higher than 1. Urbanisation level was assessed using a 5 -level scale, with levels 1 and 5 indicating the highest and lowest urbanisation levels, respectively. All the 13 independent variables were measured on a categorical or ordinal level.

\section{Data analysis}

Statistical methods included the $\chi^{2}$ test and multinomial logistic regression. The $\chi^{2}$ test examined bivariate associations, with the observation values of prevalence reported. Since the outcome variable comprised four categories, namely affective disorders, anxiety disorders, other mental disorders and no mental disorders, multinomial logistic regression was used, instead of the commonly used binomial logistic regression that analyses a 
Table 1 Characteristics of couples, 2002-2013 ( $\mathrm{N}=5643$ couples)

\begin{tabular}{|c|c|c|}
\hline Variables & Frequency & Per cent \\
\hline \multicolumn{3}{|l|}{ Insured spouse characteristics } \\
\hline \multicolumn{3}{|l|}{ Category of mental disorders } \\
\hline No mental disorders & 3404 & 60.32 \\
\hline Affective disorders & 151 & 2.68 \\
\hline Anxiety disorders & 1197 & 21.21 \\
\hline Other & 891 & 15.79 \\
\hline \multicolumn{3}{|l|}{ Gender } \\
\hline Female & 1460 & 25.87 \\
\hline Male & 4183 & 74.13 \\
\hline \multicolumn{3}{|l|}{ Age (years) } \\
\hline $16-34$ & 379 & 6.72 \\
\hline $35-44$ & 1295 & 22.95 \\
\hline $45-54$ & 1607 & 28.48 \\
\hline $55-64$ & 1185 & 21.00 \\
\hline$\geq 65$ & 1177 & 20.86 \\
\hline \multicolumn{3}{|l|}{ Occupation } \\
\hline $\begin{array}{l}\text { First category (private employee and government } \\
\text { employee) }\end{array}$ & 2884 & 51.11 \\
\hline Second category (labour union member) & 785 & 13.91 \\
\hline Third category (farmer and fisherman) & 695 & 12.32 \\
\hline $\begin{array}{l}\text { Fourth, fifth and sixth categories (soldier, social } \\
\text { security insured, and veteran and religious group } \\
\text { member) }\end{array}$ & 1279 & 22.67 \\
\hline \multicolumn{3}{|l|}{ Premium-based monthly salary (US\$) } \\
\hline$\leq 576$ & 1796 & 31.83 \\
\hline $576-760$ & 1833 & 32.48 \\
\hline $760-960$ & 413 & 7.32 \\
\hline $960-1210$ & 481 & 8.52 \\
\hline $1210-1526$ & 473 & 8.38 \\
\hline$>1526$ & 647 & 11.47 \\
\hline \multicolumn{3}{|l|}{ Comorbidity (CCI) } \\
\hline 0 & 3853 & 68.47 \\
\hline$\geq 1$ & 1774 & 31.53 \\
\hline \multicolumn{3}{|l|}{ Catastrophic illness and injury } \\
\hline Absent & 5106 & 90.48 \\
\hline Present & 537 & 9.52 \\
\hline \multicolumn{3}{|l|}{ Dependent spouse characteristics } \\
\hline \multicolumn{3}{|l|}{ Category of mental disorders } \\
\hline No mental disorders & 3230 & 57.24 \\
\hline Affective disorders & 189 & 3.35 \\
\hline Anxiety disorders & 1410 & 24.99 \\
\hline Other & 814 & 14.42 \\
\hline \multicolumn{3}{|l|}{ Gender } \\
\hline Female & 4183 & 74.13 \\
\hline Male & 1460 & 25.87 \\
\hline \multicolumn{3}{|l|}{ Age (years) } \\
\hline $16-34$ & 654 & 11.59 \\
\hline $35-44$ & 1435 & 25.43 \\
\hline $45-54$ & 1391 & 24.65 \\
\hline $55-64$ & 1152 & 20.41 \\
\hline$\geq 65$ & 1011 & 17.92 \\
\hline \multicolumn{3}{|l|}{ Comorbidity (CCI) } \\
\hline 0 & 4102 & 72.91 \\
\hline$\geq 1$ & 1524 & 27.09 \\
\hline \multicolumn{3}{|l|}{ Catastrophic illness and injury } \\
\hline Absent & 5197 & 92.10 \\
\hline Present & 446 & 7.90 \\
\hline \multicolumn{3}{|l|}{ Shared ecological characteristics } \\
\hline \multicolumn{3}{|l|}{ Region } \\
\hline Taipei & 1980 & 35.17 \\
\hline
\end{tabular}

Table 1 Continued

\begin{tabular}{lcc}
\hline Variables & Frequency & Per cent \\
\hline Northern & 869 & 15.44 \\
Central & 1076 & 19.12 \\
Southern & 752 & 13.36 \\
Southeast & 847 & 15.05 \\
Eastern & 105 & 1.87 \\
Urbanisation level & & \\
Level 1 (highest) & 1745 & 31.04 \\
Level 2 & 1665 & 29.62 \\
Level 3 & 954 & 16.97 \\
Level 4 & 739 & 13.14 \\
Level 5 (lowest) & 519 & 9.23 \\
\hline * p<0.05. & & \\
CCl, Charlson Comorbidity Index. & &
\end{tabular}

dichotomous outcome variable. Multinomial logistic regression was used for multivariate analysis, with all other covariates held constant. Since the case group was matched to compare with the control group through dual PSM, no further variables besides couple status were used in the couple-level analysis. Moreover, this study conducted collinearity diagnostics using indices including variance inflation and tolerance to detect any potentially high interrelation of characteristics between two spouses of one household. The unit of analysis in this study was primarily one individual. However, the one pair of couple or non-couple was used as the unit of analysis in the case-control analysis for concordant mental disorders. All tests were two sided and performed on an $\alpha$ value of 0.05 . Data were analysed using SAS V.9.4, SAS Institute, Cary, North Carolina, USA.

\section{RESULTS}

Table 1 presents the descriptive statistics of the study couples. The majority of the insured spouses were without any mental disorders (60.32\%). Mental disorders of the insured spouses, ranked by the prevalence rate, included anxiety, other and affective disorders $(21.21 \%, 15.79 \%$ and $2.68 \%$, respectively). Most of the dependent spouses did not receive a mental disorder diagnosis (57.24\%). The prevalence rates of anxiety, other and affective disorders among the dependents were $24.99 \%$, $14.42 \%$ and $3.35 \%$, respectively.

The $\chi^{2}$ test revealed that, among the 13 independent variables, 11 were significantly associated with the category of mental disorders among the dependent spouses, including the category of mental disorders among the insured spouses (all $\mathrm{p}<0.01$ ) (table 2). Detailed results of the two major variables showed that no mental disorders of the insured spouses were significantly associated with no mental disorders of the dependent spouses (62.22\%); affective disorders in the insured spouses were significantly associated with affective disorders in the dependent spouses (7.28\%); anxiety disorders in the insured spouses were significantly associated with anxiety disorders in dependent spouses (32.83\%); and other mental disorders of the insured spouses were significantly associated with other mental disorders of the dependent spouses (19.98\%). The highlighted areas in table 2 indicate this tendency of categorical concordance. In addition, the percentage of insured and dependent spouses, both not diagnosed with any mental disorders was $37.53 \%$ (aggregation of no mental disorders, data not shown in the table). Considering any psychiatric disorders, the prevalence rate of the aggregation of mental disorders in the couples 
Table 2 Category of mental disorders among dependent spouses, according to the characteristics of the couples, 2002-2013 ( $\chi^{2}, \mathrm{~N}=5643$ couples)

\begin{tabular}{|c|c|c|c|c|c|c|c|c|c|}
\hline \multirow[b]{2}{*}{ Variables } & \multicolumn{2}{|c|}{$\begin{array}{l}\text { No mental } \\
\text { disorders }\end{array}$} & \multicolumn{2}{|c|}{$\begin{array}{l}\text { Affective } \\
\text { disorders }\end{array}$} & \multicolumn{2}{|c|}{$\begin{array}{l}\text { Anxiety } \\
\text { disorders }\end{array}$} & \multicolumn{2}{|c|}{$\begin{array}{l}\text { Other mental } \\
\text { disorders }\end{array}$} & \multirow{2}{*}{$\begin{array}{l}\chi^{2} \\
p \text { Value }\end{array}$} \\
\hline & $\mathrm{n}_{1}$ & Per cent & $\mathrm{n}_{2}$ & Per cent & $\mathrm{n}_{3}$ & Per cent & $\mathrm{n}_{4}$ & Per cent & \\
\hline Total & 3230 & 57.24 & 189 & 3.35 & 1410 & 24.99 & 814 & 14.42 & \\
\hline \multicolumn{10}{|l|}{ Insured spouse characteristics } \\
\hline Category of mental disorders & & & & & & & & & $<0.0001^{*}$ \\
\hline No mental disorders & 2118 & $62.22 \dagger$ & 102 & 3.00 & 760 & 22.33 & 424 & 12.46 & \\
\hline Affective disorders & 80 & 52.98 & 11 & $7.28 \ddagger$ & 35 & 23.18 & 25 & 16.56 & \\
\hline Anxiety disorders & 569 & 47.54 & 48 & 4.01 & 393 & $32.83 \S$ & 187 & 15.62 & \\
\hline Other & 463 & 51.96 & 28 & 3.14 & 222 & 24.92 & 178 & $19.98 \rrbracket$ & \\
\hline Gender & & & & & & & & & $<0.0001$ * \\
\hline Female & 907 & 62.12 & 36 & 2.47 & 278 & 19.04 & 239 & 16.37 & \\
\hline Male & 2323 & 55.53 & 153 & 3.66 & 1132 & 27.06 & 575 & 13.75 & \\
\hline Age (years) & & & & & & & & & $<0.0001^{*}$ \\
\hline $16-34$ & 245 & 64.64 & 17 & 4.49 & 69 & 18.21 & 48 & 12.66 & \\
\hline $35-44$ & 814 & 62.86 & 52 & 4.02 & 265 & 20.46 & 164 & 12.66 & \\
\hline $45-54$ & 1000 & 62.23 & 46 & 2.86 & 367 & 22.84 & 194 & 12.07 & \\
\hline $55-64$ & 643 & 54.26 & 34 & 2.87 & 316 & 26.67 & 192 & 16.20 & \\
\hline$\geq 65$ & 528 & 44.86 & 40 & 3.40 & 393 & 33.39 & 216 & 18.35 & \\
\hline Occupation & & & & & & & & & $<0.0001^{*}$ \\
\hline First category (private employee and government employee) & 1755 & 60.85 & 100 & 3.47 & 658 & 22.82 & 371 & 12.86 & \\
\hline Second category (labour union member) & 471 & 60.00 & 25 & 3.18 & 177 & 22.55 & 112 & 14.27 & \\
\hline Third category (farmer and fisherman) & 348 & 50.07 & 13 & 1.87 & 203 & 29.21 & 131 & 18.85 & \\
\hline $\begin{array}{l}\text { Fourth, fifth and sixth categories (soldier, social security insured } \\
\text { and veteran and religious group member) }\end{array}$ & 656 & 51.29 & 51 & 3.99 & 372 & 29.09 & 200 & 15.64 & \\
\hline Premium-based monthly salary (US\$) & & & & & & & & & $0.0133^{*}$ \\
\hline$\leq 576$ & 984 & 54.79 & 65 & 3.62 & 485 & 27.00 & 262 & 14.59 & \\
\hline $576-760$ & 1033 & 56.36 & 54 & 2.95 & 452 & 24.66 & 294 & 16.04 & \\
\hline $760-960$ & 259 & 62.71 & 15 & 3.63 & 84 & 20.34 & 55 & 13.32 & \\
\hline $960-1210$ & 275 & 57.17 & 15 & 3.12 & 123 & 25.57 & 68 & 14.14 & \\
\hline $1210-1526$ & 297 & 62.79 & 16 & 3.38 & 117 & 24.74 & 43 & 9.09 & \\
\hline$>1526$ & 382 & 59.04 & 24 & 3.71 & 149 & 23.03 & 92 & 14.22 & \\
\hline Comorbidity (CCI) & & & & & & & & & $<0.0001^{*}$ \\
\hline 0 & 2337 & 60.65 & 129 & 3.35 & 864 & 22.42 & 523 & 13.57 & \\
\hline$\geq 1$ & 883 & 49.77 & 60 & 3.38 & 543 & 30.61 & 288 & 16.23 & \\
\hline Catastrophic illness and injury & & & & & & & & & $0.0003^{*}$ \\
\hline Absent & 2965 & 58.07 & 170 & 3.33 & 1262 & 24.72 & 709 & 13.89 & \\
\hline Present & 265 & 49.35 & 19 & 3.54 & 148 & 27.56 & 105 & 19.55 & \\
\hline \multicolumn{10}{|l|}{ Dependent spouse characteristics } \\
\hline Gender & & & & & & & & & $<0.0001^{*}$ \\
\hline Female & 2323 & 55.53 & 153 & 3.66 & 1132 & 27.06 & 575 & 13.75 & \\
\hline Male & 907 & 62.12 & 36 & 2.47 & 278 & 19.04 & 239 & 16.37 & \\
\hline Age (years) & & & & & & & & & $<0.0001$ * \\
\hline $16-34$ & 437 & 66.82 & 25 & 3.82 & 119 & 18.20 & 73 & 11.16 & \\
\hline $35-44$ & 886 & 61.74 & 63 & 4.39 & 313 & 21.81 & 173 & 12.06 & \\
\hline $45-54$ & 837 & 60.17 & 37 & 2.66 & 326 & 23.44 & 191 & 13.73 & \\
\hline $55-64$ & 620 & 53.82 & 32 & 2.78 & 328 & 28.47 & 172 & 14.93 & \\
\hline$\geq 65$ & 450 & 44.51 & 32 & 3.17 & 324 & 32.05 & 205 & 20.28 & \\
\hline Comorbidity (CCI) & & & & & & & & & $<0.0001^{*}$ \\
\hline 0 & 2655 & 64.72 & 133 & 3.24 & 799 & 19.48 & 515 & 12.55 & \\
\hline$\geq 1$ & 558 & 36.61 & 56 & 3.67 & 611 & 40.09 & 299 & 19.62 & \\
\hline Catastrophic illness and injury & & & & & & & & & $<0.0001^{*}$ \\
\hline Absent & 3023 & 58.17 & 170 & 3.27 & 1286 & 24.75 & 718 & 13.82 & \\
\hline Present & 207 & 46.41 & 19 & 4.26 & 124 & 27.80 & 96 & 21.52 & \\
\hline \multicolumn{10}{|l|}{ Shared ecological characteristics } \\
\hline Region & & & & & & & & & 0.1089 \\
\hline Taipei & 1177 & 59.44 & 73 & 3.69 & 459 & 23.18 & 271 & 13.69 & \\
\hline Northern & 512 & 58.92 & 25 & 2.88 & 216 & 24.86 & 116 & 13.35 & \\
\hline Central & 584 & 54.28 & 34 & 3.16 & 298 & 27.70 & 160 & 14.87 & \\
\hline
\end{tabular}


Table 2 Continued

\begin{tabular}{|c|c|c|c|c|c|c|c|c|c|}
\hline \multirow[b]{2}{*}{ Variables } & \multicolumn{2}{|c|}{$\begin{array}{l}\text { No mental } \\
\text { disorders }\end{array}$} & \multicolumn{2}{|c|}{$\begin{array}{l}\text { Affective } \\
\text { disorders }\end{array}$} & \multicolumn{2}{|c|}{$\begin{array}{l}\text { Anxiety } \\
\text { disorders }\end{array}$} & \multicolumn{2}{|c|}{$\begin{array}{l}\text { Other mental } \\
\text { disorders }\end{array}$} & \multirow{2}{*}{$\begin{array}{l}\chi^{2} \\
p \text { Value }\end{array}$} \\
\hline & $n_{1}$ & Per cent & $\mathrm{n}_{2}$ & Per cent & $\mathrm{n}_{3}$ & Per cent & $\mathrm{n}_{4}$ & Per cent & \\
\hline Southern & 429 & 57.05 & 20 & 2.66 & 201 & 26.73 & 102 & 13.56 & \\
\hline Southeast & 466 & 55.02 & 33 & 3.90 & 211 & 24.91 & 137 & 16.17 & \\
\hline Eastern & 61 & 58.10 & 3 & 2.86 & 20 & 19.05 & 21 & 20.00 & \\
\hline Urbanisation level & & & & & & & & & 0.3627 \\
\hline Level 1 (highest) & 1014 & 58.11 & 66 & 3.78 & 417 & 23.90 & 248 & 14.21 & \\
\hline Level 2 & 972 & 58.38 & 60 & 3.60 & 404 & 24.26 & 229 & 13.75 & \\
\hline Level 3 & 548 & 57.44 & 24 & 2.52 & 247 & 25.89 & 135 & 14.15 & \\
\hline Level 4 & 399 & 53.99 & 23 & 3.11 & 193 & 26.12 & 124 & 16.78 & \\
\hline Level 5 (lowest) & 290 & 55.88 & 15 & 2.89 & 144 & 27.75 & 70 & 13.49 & \\
\hline  & & & & & & & & & \\
\hline
\end{tabular}

reached $19.97 \%$ (data not shown). Furthermore, the prevalence rates of the concordant categories of mental disorders including affective disorders, anxiety disorders and other mental disorders were $0.19 \%, 6.96 \%$ and $3.15 \%$, respectively (data not shown). No significant collinearity was detected.

The multinomial logistic regression used no mental disorders as a referent of the outcome variable for all multivariate analyses. After adjustment for all other covariates, seven variables were significantly associated with the category of mental disorders among dependent spouses (table 3 , all $\mathrm{p}<0.05$ ). The highlighted cells in table 3 present the highest adjusted ORs and lowest $p$ values in each of the three vertical columns of a certain disorder category in dependent spouses that was significantly associated with a concordant category in the insured spouses (all $\mathrm{p}<0.01)$. Specifically, compared with no mental disorders, when the insured spouses were diagnosed with affective disorders, the dependent spouses were significantly more likely to be diagnosed with affective disorders $(\mathrm{OR}=2.914,95 \%$ CI 1.484 to $5.722, \mathrm{p}=0.0019$ ); the insured and dependent spouses were significantly more likely to be concordantly diagnosed with anxiety disorders when the insured spouses were diagnosed with anxiety $(\mathrm{OR}=1.776,95 \%$ CI 1.505 to $2.096, \mathrm{p}<0.0001)$; when the insured spouses were diagnosed with other mental disorders, the odds of both spouses being diagnosed with other mental disorders were significantly higher $(\mathrm{OR}=1.727,95 \%$ CI 1.397 to $2.134, \mathrm{p}<0.0001)$. Other factors significantly associated with the category of mental disorders among the dependent spouses included insured occupation, dependent gender, dependent age, dependent comorbidity, catastrophic illness and injury of dependent, and region (all $\mathrm{p}<0.05$ ).

The results of the couple-level propensity-matched analysis are presented in tables 4 and 5. The prevalence rates of concordant affective disorders, anxiety disorders and other mental disorders were significantly higher in couples than in noncouples (table $4 ; 0.19 \%$ vs $0.02 \%, 6.96 \%$ vs $0.02 \%, 3.15 \%$ vs $0.11 \%$, respectively; $\chi^{2}$ test, $\mathrm{p}<0.0001$ ). The multinomial logistic regression results indicated that couple status (relation) was significantly associated with categorical concordance (all $\mathrm{p}<0.05$ ). Compared with no concordance (including discordance and concordant no mental disorders), the odds of concordant affective disorders, anxiety disorders and other mental disorders were significantly higher in couples than in non-couples (table 5; $\mathrm{OR}=12.248,437.528$ and $33.031 ; 95 \%$ CI 1.581 to $94.897,61.462$ to 3114.61 and 14.630 to 74.580 , respectively).

\section{DISCUSSION}

\section{High aggregation of mental disorders}

The literature indicates the phenomenon of family clustering of mental disorders. ${ }^{2} 48$ On this basis, this study initially conducted a $2 \times 2 \chi^{2}$ test for the association between the mental disorder status of insured spouses and that of dependent spouses. Consequently, the aggregation of mental disorders and that of no mental disorders in couples were both determined $(37.53 \%$ and $19.97 \%$, respectively). The annual prevalence of psychiatric disorders in the entire population of Taiwan increased from $7.68 \%$ in 2002 to $10.54 \%$ in $2013 .{ }^{33}$ Compared with the prevalence of $33.90 \%$ (2002-2013) at the individual level, the finding that aggregate mental disorders reached the prevalence of $19.97 \%$ at the couple level warrants further attention. This high aggregation can be explained by the aforementioned cohabitation effects and emotional contagion. Predisposition similarity and familial resources for stress coping ${ }^{34}$ may denote whether psychiatric diseases will aggregate in a couple. Accordingly, the occurrence of mental disorders in a spouse can predict the mental disorder status in the partner. Previous studies have revealed the crucial role of family in coping with the mental illness of a family member, ${ }^{35}$ because a family with a psychiatric patient may not seek outside help. ${ }^{36}$ Although being the most critical stress-coping resource, an informal carer of a family would experience a substantial adaptation process of personal change concerning his or her role in social and cultural contexts. $^{37}$ The familial context in which the first spouse with mental disorders resides is inextricably interconnected with the psychological well-being of the second spouse. Therefore, a higher risk of aggregation of mental disorders emerges in couples. Furthermore, mental illness in one spouse eliciting psychological predicaments in the other spouse can be examined using the stress process model. ${ }^{34}$ When a spouse is mentally ill, the partner assumes the role of an informal carer who may undergo primary and secondary stressors. Primary stressors pertain to the direct experiences from the illness, including the perception of role captivity in the carer. When chronical stress perforates into other areas of the carer's family and work life, 
Table 3 Association between the category of mental disorders among insured spouses and that of mental disorders among dependent spouses, after adjustment for all other variables, 2002-2013 (multinomial logistic regression, $\mathrm{N}=5643$ couples)

\begin{tabular}{|c|c|c|c|c|c|c|c|c|c|}
\hline \multirow[b]{2}{*}{ Variables } & \multicolumn{3}{|c|}{$\begin{array}{l}\text { Affective disorders/no mental } \\
\text { disorders }\end{array}$} & \multicolumn{3}{|c|}{$\begin{array}{l}\text { Anxiety disorders/no mental } \\
\text { disorders }\end{array}$} & \multicolumn{3}{|c|}{$\begin{array}{l}\text { Other mental disorders/no mental } \\
\text { disorders }\end{array}$} \\
\hline & $\begin{array}{l}\text { Adjusted } \\
\mathrm{OR}\end{array}$ & $95 \% \mathrm{Cl}$ & $\mathrm{p}$ Value & $\begin{array}{l}\text { Adjusted } \\
\text { OR }\end{array}$ & $95 \% \mathrm{Cl}$ & $\mathrm{p}$ Value & $\begin{array}{l}\text { Adjusted } \\
\text { OR }\end{array}$ & $95 \% \mathrm{Cl}$ & p Value \\
\hline \multicolumn{10}{|l|}{ Insured spouse characteristics } \\
\hline \multicolumn{10}{|l|}{ Category of mental disorders } \\
\hline No mental disorders (referent) & - & - & - & - & - & - & - & - & - \\
\hline Affective disorders & 2.914 & 1.484 to 5.722 & $0.0019^{*}$ & 1.180 & 0.770 to 1.808 & 0.4475 & 1.572 & 0.979 to 2.525 & 0.0613 \\
\hline Anxiety disorders & 1.770 & 1.219 to 2.569 & $0.0027^{\star}$ & 1.776 & 1.505 to 2.096 & $<0.0001^{*}$ & 1.481 & 1.205 to 1.820 & $0.0002^{*}$ \\
\hline Other & 1.181 & 0.761 to 1.831 & 0.4580 & 1.164 & 0.961 to 1.409 & 0.1196 & 1.727 & 1.397 to 2.134 & $<0.0001^{*}$ \\
\hline \multicolumn{10}{|l|}{ Occupation } \\
\hline $\begin{array}{l}\text { First category (private employee and } \\
\text { public servant, referent) }\end{array}$ & - & - & - & - & - & - & - & - & - \\
\hline Second category (labour union member) & 0.793 & 0.435 to 1.446 & 0.4495 & 1.063 & 0.804 to 1.405 & 0.6694 & 0.887 & 0.642 to 1.225 & 0.4657 \\
\hline Third category (farmer and fisherman) & 0.522 & 0.239 to 1.139 & 0.1024 & 1.285 & 0.937 to 1.762 & 0.1203 & 1.274 & 0.886 to 1.831 & 0.1921 \\
\hline $\begin{array}{l}\text { Fourth, fifth and sixth categories } \\
\text { (soldier, social security insured and } \\
\text { veteran and religious group member) }\end{array}$ & 1.582 & 0.848 to 2.954 & 0.1497 & 1.359 & 1.040 to 1.776 & $0.0245^{*}$ & 1.419 & 1.020 to 1.973 & $0.0375^{*}$ \\
\hline \multicolumn{10}{|l|}{ Dependent spouse characteristics } \\
\hline \multicolumn{10}{|l|}{ Gender } \\
\hline \multicolumn{10}{|l|}{ Female (referent) } \\
\hline Male & 0.584 & 0.386 to 0.882 & $0.0106^{*}$ & 0.552 & 0.462 to 0.660 & $<0.0001^{*}$ & 0.980 & 0.803 to 1.197 & 0.8453 \\
\hline \multicolumn{10}{|l|}{ Age (years) } \\
\hline 16-34 (referent) & - & - & - & - & - & - & - & - & - \\
\hline $35-44$ & 1.553 & 0.874 to 2.758 & 0.1331 & 1.329 & 1.000 to 1.766 & 0.0501 & 1.290 & 0.910 to 1.828 & 0.1523 \\
\hline $45-54$ & 0.997 & 0.483 to 2.057 & 0.9939 & 1.399 & 1.002 to 1.952 & $0.0484^{*}$ & 1.493 & 0.991 to 2.249 & 0.0553 \\
\hline $55-64$ & 0.899 & 0.366 to 2.206 & 0.8156 & 1.500 & 1.004 to 2.242 & $0.0479^{*}$ & 1.442 & 0.882 to 2.360 & 0.1448 \\
\hline$\geq 65$ & 0.852 & 0.291 to 2.495 & 0.7707 & 1.397 & 0.870 to 2.243 & 0.1659 & 1.808 & 1.017 to 3.213 & $0.0435^{*}$ \\
\hline \multicolumn{10}{|l|}{ Comorbidity (CCI) } \\
\hline 0 (referent) & - & - & - & - & - & - & - & - & - \\
\hline$\geq 1$ & 2.078 & 1.438 to 3.002 & $<0.0001^{*}$ & 3.403 & 2.909 to 3.981 & $<0.0001^{*}$ & 2.285 & 1.888 to 2.764 & $<0.0001$ * \\
\hline \multicolumn{10}{|l|}{ Catastrophic illness and injury } \\
\hline Absent (referent) & - & - & - & - & - & - & - & - & - \\
\hline Present & 1.485 & 0.881 to 2.506 & 0.1381 & 0.883 & 0.686 to 1.137 & 0.3346 & 1.326 & 1.008 to 1.743 & $0.0434^{*}$ \\
\hline \multicolumn{10}{|l|}{ Shared ecological characteristics } \\
\hline \multicolumn{10}{|l|}{ Region } \\
\hline Taipei (referent) & - & - & - & - & - & - & - & - & - \\
\hline Northern & 0.860 & 0.509 to 1.455 & 0.5747 & 1.072 & 0.854 to 1.346 & 0.5473 & 0.976 & 0.739 to 1.289 & 0.8660 \\
\hline Central & 1.006 & 0.622 to 1.627 & 0.9799 & 1.287 & 1.043 to 1.589 & $0.0188^{*}$ & 1.191 & 0.923 to 1.537 & 0.1789 \\
\hline Southern & 0.837 & 0.464 to 1.507 & 0.5524 & 1.083 & 0.847 to 1.384 & 0.5257 & 0.975 & 0.723 to 1.315 & 0.8667 \\
\hline Southeast & 1.256 & 0.791 to 1.995 & 0.3338 & 1.121 & 0.901 to 1.396 & 0.3051 & 1.288 & 0.996 to 1.664 & 0.0537 \\
\hline Eastern & 0.864 & 0.251 to 2.970 & 0.8163 & 0.779 & 0.445 to 1.364 & 0.3828 & 1.522 & 0.866 to 2.675 & 0.1447 \\
\hline
\end{tabular}

secondary stressors emerge and affect the well-being of the carer. $^{14} 38$ Furthermore, a longitudinal study revealed that the association between depressive symptoms of husbands and the subsequent depressive symptoms of wives was stronger among couples reporting marital distress compared with those reporting higher marital satisfaction. ${ }^{17}$ Briefly, mental disorders are costly and debilitating for ill and healthy spouses. ${ }^{39}$ Therefore, the coping strategies of an informal carer and formal social support outside the family are pivotal to the mental health concerns in couples. ${ }^{18} 3637$ Releasing the care burden imposed on the healthy spouse is key in the intervention to prevent the new development of psychiatric morbidity and to provide the mentally ill spouse an opportunity to recover in a supportive family environment. ${ }^{5}$

\section{Phenomenon of parallel contagion}

This study identified three concordant categories of mental disorders in married couples. The highlighted cells in table 2 present the row percentages of concordance for each category, including no mental disorders, affective disorders, anxiety disorders and other mental disorders. Table 3 further provides the adjusted ORs for the three concordances in a manner mirroring the findings presented in table 2 . An additional analysis was performed using mental disorder status of dependent spouses as the independent variable and that of insured spouses as the outcome variable. This analysis which swapped the two major dependent and independent variables substantially generated same results (data not shown). Insured and dependent spouses were most likely to experience a concordant category of mental 
Table 4 Concordant mental disorders in couples versus non-couples, 2002-2013 (with dual propensity score matching for gender, age and Charlson Comorbidity Index; $\chi^{2}$ test; $N=11286$ pairs)

\begin{tabular}{|c|c|c|c|c|c|c|c|c|c|}
\hline \multirow[b]{2}{*}{ Variables } & \multicolumn{2}{|c|}{$\begin{array}{l}\text { Concordant } \\
\text { affective disorders }\end{array}$} & \multicolumn{2}{|c|}{$\begin{array}{l}\text { Concordant anxiety } \\
\text { disorders }\end{array}$} & \multicolumn{2}{|c|}{$\begin{array}{l}\text { Concordant other } \\
\text { mental disorders }\end{array}$} & \multicolumn{2}{|c|}{ No concordance } & \multirow{2}{*}{$\begin{array}{l}\chi^{2} \\
p \text { Value }\end{array}$} \\
\hline & $\mathrm{n}_{1}$ & Per cent & $\mathrm{n}_{2}$ & Per cent & $\mathrm{n}_{3}$ & Per cent & $\mathrm{n}_{4}$ & Per cent & \\
\hline Relation & & & & & & & & & $<0.0001^{*}$ \\
\hline Non-couple & 1 & 0.02 & 1 & 0.02 & 6 & 0.11 & 5635 & 99.86 & \\
\hline Couple & 11 & 0.19 & 393 & 6.96 & 178 & 3.15 & 5061 & 89.69 & \\
\hline
\end{tabular}

${ }^{*} p<0.05$, with 1:1 propensity score matching according to gender, age and Charlson Comorbidity Index for the four individuals in the couples and non-couple pairs.

Table 5 Association between couple status and concordant mental disorders, 2002-2013 (with dual propensity score matching for gender, age and Charlson Comorbidity Index; multinomial logistic regression; N=11286 pairs)

\begin{tabular}{|c|c|c|c|c|c|c|c|c|c|}
\hline \multirow[b]{2}{*}{ Variables } & \multicolumn{3}{|c|}{$\begin{array}{l}\text { Concordant affective disorders/no } \\
\text { concordance }\end{array}$} & \multicolumn{3}{|c|}{$\begin{array}{l}\text { Concordant anxiety disorders/no } \\
\text { concordance }\end{array}$} & \multicolumn{3}{|c|}{$\begin{array}{l}\text { Concordant other mental disorders /no } \\
\text { concordance }\end{array}$} \\
\hline & OR & $95 \% \mathrm{Cl}$ & p Value & OR & $95 \% \mathrm{Cl}$ & p Value & OR & $95 \% \mathrm{Cl}$ & p Value \\
\hline \multicolumn{10}{|l|}{ Relation } \\
\hline Non-couple & - & - & - & - & - & - & - & - & - \\
\hline Couple & 12.248 & 1.581 to 94.897 & $0.0165^{*}$ & 437.528 & 61.462 to 3115.25 & $<0.0001^{*}$ & 33.031 & 14.630 to 74.580 & $<0.0001^{*}$ \\
\hline
\end{tabular}

disorders among the three categories. If one spouse was diagnosed with affective disorders, the other spouse would most likely undergo affective disorders correspondingly. If one spouse experienced anxiety disorders, the same type of disease might occur in the other spouse. The phenomenon coherently applied to other mental disorders. This particular finding, further confirmed strongly in the matched case-control analysis, was named the phenomenon of parallel contagion, an empirical derivative from the theory of emotional contagion. ${ }^{14}$ Signalling the concordance in mental illness, parallel contagion justifies the necessity of epidemiological prevention, particularly for the same type of mental disorders in couples. Notably, the contagion identified is not exclusive of different categories of mental disorders. Dependent spouses were also more likely to undergo affective disorders even if insured spouses were diagnosed with anxiety disorders $(\mathrm{OR}=1.770)$; a strong association was observed between anxiety disorders in insured spouses and other mental disorders in dependent spouses $(\mathrm{OR}=1.481)$. Although the association between the categories of mental disorders among insured spouses and those of dependent spouses could be nonparallel (discordant), the phenomenon of parallel contagion is evident and thus delivers essential clinical implications. Future research is required to explore the concordance within other categories of mental disorders in couples.

\section{Other characteristics predicting risk}

Soldiers, social security insureds and veterans were closely related to higher odds of anxiety and other mental disorders, and this finding echoes the findings of previous studies. ${ }^{40}{ }^{41}$ As the possibility of two spouses of a household sharing common occupational stress is high, ${ }^{42}$ the occupation of insured spouses is a determinant of the category of mental disorders among dependent spouses.

The present study has certain limitations that should be addressed. First, the secondary data used did not include information on health behaviour and perceived stress; therefore, the absence of such information might attenuate the statistical testing power. Nevertheless, this study fully used all obtainable data for analysis. Second, the actual length of marriage and cohabitation could not be ascertained from the NHIRD, thus limiting further analysis in this study. Finally, spouses who could be identified from the database were limited to the insureddependent relationship. The study findings must be cautiously extrapolated to all other scenarios.

\section{CONCLUSION}

This study demonstrates that shared environmental factors contribute to the development of mental diseases in couples. When one spouse is diagnosed with mental disorders, the other spouse is at risk of mental illness. A family clustering of mental disorders was further determined to demonstrate the phenomenon of parallel contagion. The concordance of mental disorders in couples was identified in the aggregation form of affectiveaffective, anxiety-anxiety and other-other disorders. Although different from conventional contagion in epidemiology, the phenomenon of parallel contagion substantially carries clinical implications in developing the prospective direction of family-

\section{What this study adds?}

- The prevalence rates for concordant categories of mental disorder are $0.19 \%$ for affective disorders, $6.96 \%$ for anxiety disorders and $3.15 \%$ of other mental disorders.

- Two spouses are significantly likely to be diagnosed with the same category of mental disorders including affective, anxiety and other disorders.

- Other associated factors include age, occupation, comorbidity and region.

- This study proposes 'the phenomenon of parallel contagion'. A category of mental disorder in one spouse is a determinant of that in the other spouse. 


\section{What is already known on this subject?}

- The aggregation of mental disorders in couples has been reported by prior research, which indicates the effect of shared environment on psychiatric epidemiology and warrants attention.

- The concordant categories of mental disorders in couples and the associated factors remain fragmented and inconclusive.

based mental health practice. Establishing an external support system toward mentally vulnerable family members is a policy priority. Policymakers should target spouses whose married partners were mentally ill by using the risk factors identified by this study for preventing mental disorders, particularly the same category of mental disorders.

Acknowledgements The authors are grateful to Taiwan's National Health Research Institutes for providing the NHIRD.

Contributors J-YW proposed the study idea, designed the study, interpreted the analysis and wrote the first draft of the manuscript. $\mathrm{M}-\mathrm{HH}$ contributed to the theoretical construction and revised the manuscript. P-CL contributed to the literature review and performed the statistical analyses. C-SL provided guidance and aided in proofreading the manuscript. J-DC participated in critical discussion and edited the manuscript.

Funding This research was supported by Ministry of Science and Technology, Taipei, Taiwan (grant no. NSC 102-2410-H-039-006-SS2 and MOST 104-2410-H-039-006).

Competing interests None declared.

Ethics approval The institutional review board at China Medical University Hospital.

Provenance and peer review Not commissioned; externally peer reviewed.

Open Access This is an Open Access article distributed in accordance with the Creative Commons Attribution Non Commercial (CC BY-NC 4.0) license, which permits others to distribute, remix, adapt, build upon this work non-commercially, and license their derivative works on different terms, provided the original work is properly cited and the use is non-commercial. See: http://creativecommons.org/ licenses/by-nc/4.0/

\section{REFERENCES}

1 Lee JS, Joo EJ, Choi KS. Perceived stress and self-esteem mediate the effects of work-related stress on depression. Stress Health 2013;29:75-81.

2 Isomura K, Boman M, Ruck C, et al. Population-based, multi-generational family clustering study of social anxiety disorder and avoidant personality disorder. Psycho Med 2015;45:1581-9.

3 Mataix-Cols D, Boman M, Monzani B, et al. Population-based, multigenerational family clustering study of obsessive-compulsive disorder. JAMA Psychiatry 2013:70:709-17.

4 Hippisley-Cox J, Coupland C, Pringle $M$, et al. Married couples' risk of same disease: cross sectional study. BMJ 2002:325:636.

5 Joutsenniemi K, Moustgaard H, Koskinen S, et al. Psychiatric comorbidity in couples: a longitudinal study of 202,959 married and cohabiting individuals. Soc Psychiatry Psychiatr Epidemiol 2011;46:623-33.

6 Wittmund B, Wilms HU, Mory C, et al. Depressive disorders in spouses of mentally ill patients. Soc Psychiatry Psychiatr Epidemiol 2002:37:177-82.

7 Maes $\mathrm{HH}$, Neale MC, Kendler KS, et al. Assortative mating for major psychiatric diagnoses in two population-based samples. Psychol Med 1998;28:1389-401.

8 Kendler KS, Ohlsson $\mathrm{H}$, Sundquist $\mathrm{K}$, et al. Environmental clustering of drug abuse in households and communities: multi-level modeling of a national Swedish sample. Soc Psychiatry Psychiatr Epidemiol 2015;50:1277-84

9 Agrawal A, Heath AC, Grant JD, et al. Assortative mating for cigarette smoking and for alcohol consumption in female Australian twins and their spouses. Behav Genet 2006;36:553-66
10 Reynolds CA, Barlow T, Pedersen NL. Alcohol, tobacco and caffeine use: spouse similarity processes. Behav Genet 2006:36:201-15.

11 Knuiman MW, Divitini ML, Welborn TA, et al. Familial correlations, cohabitation effects, and heritability for cardiovascular risk factors. Ann Epidemiol 1996;6:188-94.

12 Knuiman MW, Divitini ML, Bartholomew HC, et al. Spouse correlations in cardiovascular risk factors and the effect of marriage duration. Am J Epidemiol 1996;143:48-53.

13 Bookwala J, Schulz R. Spousal similarity in subjective well-being: the cardiovascular health study. Psychol Aging 1996;11:582-90.

14 Goodman CR, Shippy RA. Is it contagious? Affect similarity among spouses. Aging Ment Health 2002;6:266-74.

15 Hill R. Generic features of family under stress. Social Casework 1958:49:139-50

16 Pierce GR. Social support in couples: marriage as a resource in times of stress (Book). Journal of Marriage \& Family 1997:59:494-5.

17 Kouros CD, Cummings EM. Longitudinal associations between husbands' and wives' depressive symptoms. J Marriage Fam 2010;72:135-47.

18 Benazon NR, Coyne JC. The next step in developing an interactional description of depression? Psychological Inquiry 1999:10:279-304.

19 Tower RB, Kasl SV. Depressive symptoms across older spouses and the moderating effect of marital closeness. Psychol Aging 1995; 10:625-38.

20 Falba TA, Sindelar JL. Spousal concordance in health behavior change. Health Serv Res 2008;43:96-116.

21 Homish GG, Leonard KE. Spousal influence on general health behaviors in a community sample. Am J Health Behav 2008;32:754-63.

22 Stimpson JP, Masel MC, Rudkin L, et al. Shared health behaviors among older Mexican American spouses. Am J Health Behav 2006;30:495-502.

23 Bronfenbrenner U. The ecology of human development: experiments by design and nature. Cambridge, MA: Harvard University Press, 1979.

24 Idstad M, Roysamb E, Tambs K. The effect of change in mental disorder status on change in spousal mental health: the HUNT study. Soc Sci Med 2011;73:1408-15.

25 Sareen J, Afifi TO, McMillan KA, et al. Relationship between household income and mental disorders: findings from a population-based longitudinal study. Arch Gen Psychiatry 2011;68:419-27.

26 Dinkel A, Kremsreiter K, Marten-Mittag B, et al. Comorbidity of fear of progression and anxiety disorders in cancer patients. Gen Hosp Psychiatry 2014;36:613-9.

27 Ducat L, Philipson LH, Anderson BJ. The mental health comorbidities of diabetes. JAMA 2014;312:691-2.

28 Fan ZJ, Bonauto DK, Foley MP, et al. Occupation and the prevalence of current depression and frequent mental distress, WA BRFSS 2006 and 2008. Am J Ind Med 2012;55:893-903.

29 Wulsin L, Alterman T, Bushnell P, et al. Prevalence rates for depression by industry: a claims database analysis. Soc Psychiatry Psychiatr Epidemiol 2014;49:1805-21.

30 Malard L, Chastang JF, Niedhammer I. Changes in major depressive and generalized anxiety disorders in the national French working population between 2006 and 2010. J Affect Disord 2015:178:52-9.

31 Ruiz-Grosso P, Ramos M, Samalvides F, et al. Common mental disorders in public transportation drivers in Lima, Peru. PLoS ONE 2014:9:e101066.

32 Deyo RA, Cherkin DC, Ciol MA. Adapting a clinical comorbidity index for use with ICD-9-CM administrative databases. J Clin Epidemiol 1992;45:613-9.

33 Ministry of health and welfare. Hospital and Clinical Statistics. 2016 (cited 15 August 2016). http://www.mohw.gov.tw/EN/Ministry/Statistic.aspx?f list_no=474

34 Pearlin LI, Mullan JT, Semple SJ, et al. Caregiving and the stress process: an overview of concepts and their measures. Gerontologist 1990;30:583-94.

35 Wouters E, Masquillier C, le Roux Booysen F. The Importance of the family: a longitudinal study of the predictors of depression in HIV patients in South Africa. AIDS Behav 2016:20:1591-602.

36 Thompson G, McBride RB, Hosford CC, et al. Resilience among medical students: the role of coping style and social support. Teach Learn Med 2016:28:174-82.

37 Moreno-Camara S, Palomino-Moral PA, Moral-Fernandez L, et al. [Problems in the process of adapting to change among the family caregivers of elderly people with demential. Gac Sanit 2016:30:201-7.

38 Goodman CR, Zarit SH, Steiner VL. Personal orientation as a predictor of caregiver strain. Aging Ment Health 1997:1:149-57. 9p.

39 Trivedi RB, Post EP, Sun $\mathrm{H}$, et al. Prevalence, comorbidity, and prognosis of mental health among US veterans. Am J Public Health 2015;105:2564-9. 6p.

40 Hageman I, Pinborg A, Andersen HS. Complaints of stress in young soldiers strongly predispose to psychiatric morbidity and mortality: Danish national cohort study with 10-year follow-up. Acta Psychiatr Scand 2008;117:148-55.

41 Diala CC, Muntaner C, Walrath C. Gender, occupational, and socioeconomic correlates of alcohol and drug abuse among US rural, metropolitan, and urban residents. Am J Drug Alcohol Abuse 2004;30:409-28.

42 Tsukahara I. The effect of family background on occupational choice. Labour 2007:21:871-90. 